\section{Chinese securities investment funds: the role of luck in performance}

\author{
Jun Gao, Niall O'Sullivan and Meadhbh Sherman \\ Department of Economics, University College Cork, Cork, Ireland
}

\section{Chinese securities investment funds}

Received 2 July 2020 Revised 8 January 2021 12 June 2021

3 September 2021

14 September 2021

Abstract

Purpose - The Chinese fund market has witnessed significant developments in recent years. However, although there has been a range of studies assessing fund performance in developed industries, the rapidly developing fund industry in China has received very little attention. This study aims to examine the performance of open-end securities investment funds investing in Chinese domestic equity during the period May 2003 to September 2020. Specifically, applying a non-parametric bootstrap methodology from the literature on fund performance, the authors investigate the role of skill versus luck in this rapidly evolving investment funds industry.

Design/methodology/approach - This study evaluates the performance of Chinese equity securities investment funds from 2003-2020 using a bootstrap methodology to distinguish skill from luck in performance. The authors consider unconditional and conditional performance models.

Findings - The bootstrap methodology incorporates non-normality in the idiosyncratic risk of fund returns, which is a major drawback in "conventional" performance statistics. The evidence does not support the existence of "genuine" skilled fund managers. In addition, it indicates that poor performance is mainly attributable to bad stock picking skills.

Practical implications - The authors find that the top-ranked funds with positive abnormal performance are attributed to "good luck" not "good skill" while the negative abnormal performance of bottom funds is mainly due to "bad skill." Therefore, sensible advice for most Chinese equity investors would be against trying to "pick winners funds" among Chinese securities investment funds but it would be recommended to avoid holding "losers." At the present time, investors should consider other types of funds, such as index/tracker funds with lower transactions. In addition, less risk-averse investors may consider Chinese hedge funds [Zhao (2012)] or exchange-traded fund [Han (2012)].

Originality/value - The paper makes several contributions to the literature. First, the authors examine a wide range (over 50) of risk-adjusted performance models, which account for both unconditional and conditional risk factors. The authors also control for the profitability and investment risks in Fama and French (2015). Second, the authors select the "best-fit" model across all risk-adjusted models examined and a single "best-fit" model from each of the three classes. Therefore, the bootstrap analysis, which is mainly based on the selected best-fit models, is more precise and robust. Third, the authors reduce the possibility that findings may be sampleperiod specific or may be a survivor (upward) biased. Fourth, the authors consider further analysis based on subperiods and compare fund performance in different market conditions to provide more implications to investors and practitioners. Fifth, the authors carry out extensive robustness checks and show that the findings are robust in relation to different minimum fund histories and serial correlation and heteroscedasticity adjustments. Sixth, the authors use higher frequency weekly data to improve statistical estimation.

Keywords Fund performance, Factor models, Bootstrap analysis, Fama-French five factors, Skill versus luck, Bootstrap methodology

Paper type Research paper

Published by Emerald Publishing Limited. This article is published under the Creative Commons Attribution (CC BY 4.0) licence. Anyone may reproduce, distribute, translate and create derivative works of this article (for both commercial and non-commercial purposes), subject to full attribution to the original publication and authors. The full terms of this licence may be seen at http:// creativecommons.org/licences/by/4.0/legalcode
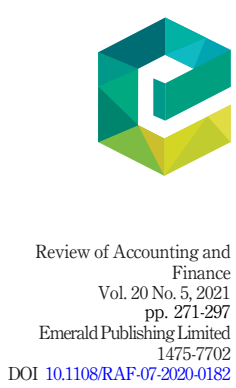
$\mathrm{RAF}$

20,5

272

\section{Introduction}

The Chinese fund market has witnessed significant developments in recent years. This fact motivates a considerable amount of research assessing fund performance in this newer and less developed market. However, as an emerging industry, the Chinese fund industry is still under-explored and not well-documented compared with developed industries, such as the USA and the UK. This motivates us to study Chinese funds. Our study examines the performance of open-end securities investment funds investing in Chinese domestic equity during the period May 2003 to September 2020. Specifically, applying a non-parametric bootstrap methodology from the literature on fund performance, we investigate the role of skill versus luck in this rapidly evolving fund industry.

Past studies of fund abnormal performance in the Chinese market use "conventional" statistical measures, such as Capital Asset Pricing Model (CAPM) alpha (Jensen, 1968), the Fama and French (1993) three-factor model and the Carhart (1997) four-factor model. Jensen (1968) develops the CAPM, which seeks to explain the cross-section of expected returns. Fama and French (1993) added two additional factors to CAPM to capture returns attributable to the size and value risk factors. Carhart (1997) extended the Fama and French (1993) three-factor model by adding a momentum risk factor.

Findings based on these performance models suggest little or no significant abnormal return on average (Zhou and Shi, 2004; Xiao and Yang, 2005; Luo, 2011; Gao et al., 2020). The preponderance of evidence from developed mutual fund industries, such as the USA and the UK also fail to find robust evidence of positive abnormal performance - Carhart (1997), Christopherson et al. (1998), Hendricks et al. (1993), Blake and Timmermann (1998), Quigley and Sinquefield (2000), Fletcher and Forbes (2002) and Cuthbertson et al. (2008).

However, inferences regarding risk-adjusted performance based on such approaches above give rise to two issues - the requirement of normality in fund returns and difficulty in distinguishing skill from luck in performance.

First, these parametric tests require fund returns to be normally distributed as nonnormality may lead to invalid statistical inferences. However, empirical evidence from Section 5 in our study shows that there exists a high degree of non-normality for around $90 \%$ of Chinese securities investment funds examined. Hence, alphas from these model estimations may not satisfy the requirement of a normal distribution. Moreover, these highly non-normally distributed residuals are particularly prevalent among the best and the worst performing funds, which attract the most attention among investors. One possible explanation suggests that these non-normal fund returns result from holding derivatives to hedge return outcomes. Kosowski et al. (2006) point out that according to the central limit theorem, the returns on a large, well-diversified and equal-weighted portfolio of securities should approximate normality. However, these characteristics do not appear in most funds in practice as funds either do not or cannot achieve the required granular level of diversification. As a non-parametric technique, however, the bootstrap methodology in our study incorporates non-normality in the idiosyncratic risk of fund returns.

Second, it is possible that some funds earn positive (negative) abnormal returns simply due to good (bad) luck. Previous studies of mutual fund performance that use conventional statistical measures generally find little evidence of positive abnormal performance but strong evidence of poor performance (Hendricks et al., 1993; Carhart, 1997; Christopherson et al., 1998; Blake and Timmermann, 1998; Quigley and Sinquefield, 2000; Fletcher and Forbes, 2002; Cuthbertson et al., 2008). Our study directly addresses the issue of "skill versus luck" using the bootstrap methodology.

The bootstrap methodology used in our study is first introduced in Kosowski et al. (2006). The procedure simulates fund returns under the null hypothesis of zero abnormal 
performance. The simulated returns are used to construct non-parametric distributions of abnormal performance under the null, i.e. the distribution of what abnormal performance may look like simply due to random sampling variation in returns, i.e. chance (or luck). These distributions may then be used to estimate non-parametric $p$-values for "actual" abnormal return estimates (based on actual data). The procedure permits this to be done at each point in the cross-sectional distribution of performance, i.e. for the best fund, second best fund and so on, down to the worst fund.

The Kosowski et al. (2006) study selects the Carhart four-factor-based models as the "best-fit" models within each of the categories of unconditional and conditional beta models. The authors report a $p$ value of 0.02 for the top ranked fund, which indicates the US top ranked fund does have genuine security selection ability as there is only a $2 \%$ probability of observing this outperformance in the best fund by chance alone. The authors also argue that the bottom ranked funds perform even worse than may be due to bad luck. Huang et al. (2020) develop a new bootstrap procedure and evaluate mutual fund performance based on monthly returns from January 1980 to December 2018 for all US actively managed equity funds. They find that skilled funds are more engaged in active management and hold stocks with higher expected returns.

The bootstrap methodology of Kosowski et al. (2006) is applied to the UK mutual fund industry by Cuthbertson et al. (2008). The study evaluates 935 equity Unit Trusts and OpenEnded Investment Companies over the period 1975-2002. The Fama and French threefactor-based models are chosen as the "best-fit" models as consistent with other UK studies, the authors find that the momentum risk factor is not statistically significant in the UK case (Blake and Timmermann, 1998; Quigley and Sinquefield, 2000; Tonks, 2004). The Cuthbertson et al. (2008) paper shows that outperformance is not simply due to good luck as around $2 \%$ of top ranked UK mutual funds exhibit good performance attributable to genuine stock selection skills. However, their findings regarding the actively-managed fund industry as a whole indicate that the funds that earn a positive abnormal alpha do not possess genuine stock picking ability on average.

In terms of poor performing funds, the authors demonstrate that most of these funds underperformed over the period mainly due to bad skill rather than bad luck, which is also consistent with the conclusion reached in the Kosowski et al. (2006) study regarding US bad performing funds. However, using a competitive model, Berk and Green (2004) draw a different conclusion - that most underperforming funds demonstrate bad luck, as bad skill may cause a large outflow from funds and in equilibrium the return on surviving funds should equal the return on a passively-managed fund (index fund).

As an emerging market, the Chinese fund industry is not as well-explored as the USA and the UK. Previous studies on Chinese securities investment fund performance indicate no significant positive abnormal return on average - although a small number of funds do produce stock selection ability (Zhou and Shi, 2004; Xiao and Yang, 2005; Zhao and Wang, 2007; Luo, 2011; Gao et al., 2020). However, past papers are principally based on parametric tests, and hence, may lead to difficulties around normality and skill versus luck as discussed above. Only a few studies evaluate Chinese fund performance using non-parametric bootstrap approaches to address these issues. Yang and Liu (2017) implement the bootstrap procedure on Chinese open-end equity securities investment funds over the period 20022013 based on the unconditional Carhart (1997) four-factor model and find that positive abnormal performance is attributable to good luck only while underperformance is due to bad skill. Yan (2020) examines skill versus luck in the Chinese fund industry during 20042017 and reaches broadly similar findings to those in Yang and Liu (2017) for both index and actively-managed funds. Xu and Liu (2009), however, draw different conclusions. The 
authors investigate the role of luck in Chinese fund performance over the period 2003-2008 based on the unconditional Fama and French (1993) three-factor model and the Carhart (1997) four-factor model and find that poor performers display bad skills, which is consistent with the findings from the two studies. However, the authors also find that there exists stock selection ability among a relatively small number of top performing funds. Similarly, Chen and Chen (2017) find that superior stock-picking abilities may actually exist among a small number of Chinese funds while bad performance is mainly due to bad skill over the period 2001-2012.

Overall, in relation to the lower end of the performance distribution, previous studies make broadly consistent conclusions that poor performers produce "genuine" bad skills. Regarding the upper end of the performance distribution, however, findings from previous research are contradictory.

The aforementioned studies on the skill versus luck issue in the Chinese fund industry do not test the relative performance of different models. Furthermore, they do not consider conditional factor models and so may fail to take account of changing market information about the expected returns and risks of individual securities. The Gao et al. paper (2020) examines a wide range of risk-adjusted performance measures in three classes and finds that the open-end securities investment funds do not earn abnormal returns on average while superior stock selection ability is found among the managers of a small number (around top $2 \%$ ) of funds. The authors also apply estimation diagnostics and select the unconditional Fama and French (1993) three-factor model as the "best-fit" model among all three categories for the Chinese industry. Their findings, however, are based on conventional statistical measures only, and hence, do not incorporate non-normality in the idiosyncratic risk of fund returns to distinguish skill from luck in fund performance. In addition, the Gao et al. (2020) paper does not take the profitability and investment risk factors in Fama and French (2015) into consideration.

In our paper, we first examine over 50 risk-adjusted performance models including the recent Fama and French (2015) five-factor model. We find that although the Chinese fund industry displays insignificant abnormal performance on average, a small portion of funds (around 3\%) are found to yield significant positive alphas while around $10 \%$ of them yield significant negative alphas. However, it is possible that some funds earn significant positive (negative) abnormal returns simply due to good (bad) luck. We select a single "best-fit" model from each of the three classes as follows: unconditional models, conditional beta models and conditional alpha-beta models and then implement the bootstrap methodology to incorporate non-normality and directly address the issue of "skill versus luck." Hence, our bootstrap analysis mainly based on the selected best-fit models is more precise and robust. In addition, our sample period of 2003-2020, which covers periods of changing market conditions and major market/industry events, to our knowledge, is the longest among studies on the Chinese fund industry. We also consider further analysis based on subperiods as the comparison of fund performance in different market conditions could have significant implications for investors and practitioners. Also, our analysis is based on higher frequency weekly data while the aforementioned studies analyze the role of luck in Chinese fund performance based on monthly data. The history of the Chinese fund industry is relatively short, and hence, using monthly return data questions the robustness of findings based on relatively few observations (particularly when considering analysis based on shorter sub-periods). Hence, we examine weekly returns data to mitigate this potential drawback.

The rest of the study proceeds as follows. Section 2 describes our data set. Sections 3 and 4 discuss the parametric risk-adjusted performance measures and the non-parametric 
bootstrap methodology, respectively. Empirical results for relative performance (and model selection) and bootstrap analysis are presented in Sections 5 and 6, respectively. Section 7 concludes.

\section{Data}

\subsection{Industry history and size}

The Chinese securities investment fund industry was established in October 1991 while open-end securities investment funds were first issued in December 2001. The Chinese openend fund industry has been developing extremely fast since 2003 and by September 2020 there were 6,538 open-end securities investment funds in the marketplace.

During the past decade (from 2010 to 2020), the total net asset value of the Chinese securities investment fund industry increased from $¥ 25,275.43 \mathrm{bn}$ (US\$3,902.5264bn) to $¥ 178,047.16 \mathrm{bn}$ (US $\$ 27,490.4815 \mathrm{bn}$ ) while the corresponding figure for the US only grew from around US $\$ 15.88 \mathrm{tn}$ to US $\$ 21.3 \mathrm{tn}$. The fund industry in China, as an emerging industry, was developing much faster than developed fund industries, such as the US mutual fund industry (albeit from a lower base). This significant growth is one of the motivations for studying the Chinese fund industry. A breakdown of the historical data for the Chinese fund industry is presented in Table 1.

\subsection{Institutional and regulatory framework}

The Chinese fund market has witnessed significant changes in recent years. As an emerging market, the Chinese fund industry may be less developed and less efficient. The institutional

\begin{tabular}{|c|c|c|c|c|}
\hline Year & No. of funds & No. of closed-end funds & No. of open-end funds & $\begin{array}{l}\text { Total net asset value of } \\
\text { fund industry (billion) }\end{array}$ \\
\hline 1998 & 5 & 5 & 0 & $¥ 103.64$ \\
\hline 1999 & 19 & 19 & 0 & $¥ 484.16$ \\
\hline 2000 & 33 & 33 & 0 & $¥ 845.91$ \\
\hline 2001 & 51 & 48 & 3 & $¥ 818.10$ \\
\hline 2002 & 67 & 54 & 13 & $¥ 1,112.92$ \\
\hline 2003 & 104 & 54 & 50 & $¥ 1,572.74$ \\
\hline 2004 & 161 & 54 & 107 & $¥ 3,246.40$ \\
\hline 2005 & 222 & 54 & 168 & $¥ 4,607.48$ \\
\hline 2006 & 321 & 53 & 268 & $¥ 8,552.71$ \\
\hline 2007 & 366 & 35 & 331 & $¥ 32,853.28$ \\
\hline 2008 & 474 & 33 & 441 & $¥ 19,427.37$ \\
\hline 2009 & 621 & 33 & 588 & $¥ 26,829.61$ \\
\hline 2010 & 785 & 31 & 754 & $¥ 25,275.43$ \\
\hline 2011 & 835 & 31 & 804 & $¥ 21,918.40$ \\
\hline 2012 & 1,124 & 31 & 1,093 & $¥ 28,661.00$ \\
\hline 2013 & 1,474 & 30 & 1,444 & $¥ 30,020.71$ \\
\hline 2014 & 1,897 & 134 & 1,763 & $¥ 45,354.00$ \\
\hline 2015 & 2,722 & 164 & 2,558 & $¥ 83,972.00$ \\
\hline 2016 & 3,867 & 303 & 3,564 & $¥ 91,593.00$ \\
\hline 2017 & 4,841 & 480 & 4,361 & $¥ 115,997.00$ \\
\hline 2018 & 5,626 & 669 & 4,857 & $¥ 130,347.00$ \\
\hline 2019 & 6,544 & 861 & 5,683 & $¥ 147,672.51$ \\
\hline 2020 & 7,644 & 1,106 & 6,538 & $¥ 178,047.16$ \\
\hline
\end{tabular}

\section{Chinese securities investment funds}

275

Source: www.amac.org.cn/ (Asset Management Association of China)

Table 1.

Breakdown of historical data of Chinese securities investment fund industry 
and regulatory framework in China is quite different from the fund industry in developed capital markets. A distinct social and economic environment is created by the strong culture and the nation's socialist tradition. For example, fund allocation, even by private firms, must often observe some non-market motivations, such as political motivations. In addition, there are still limitations on private firms acquiring and allocating resources and conducting operations (Peng and Heath, 1996; Peng, 2001). Also, compared with the USA and the UK, there are fewer experienced managers in the Chinese capital market (Peng, 2001). Therefore, the institutional and regulatory environment in China provides an attractive context to study the Chinese fund industry.

\subsection{Data sets used in this study}

The fund data set used in this study (778 funds) includes as many non-surviving funds (119) as possible in an attempt to mitigate survivorship bias. By definition, a non-surviving fund is one that has existed for some of the sample period but has not survived until the end of the period. Situations such as mergers or takeovers may cause funds to cease. In addition, underperformance may have forced some non-surviving funds to close. Average performance may be biased upwards by the latter situation, and hence, it is important to control for survivorship bias while assessing fund performance.

The securities investment fund returns data have been taken from the RESSET Database[1]. We use weekly returns instead of monthly returns from May 2003 to September 2020 to enlarge the sample size and to obtain more observations. All fund returns are fully contiguous. All fund returns are calculated bid price to bid price with (gross) income reinvested. The returns are gross of (or before) the load fee but net of the annual management fees imposed and are measured gross of taxes on dividends and capital gains. This is appropriate as returns on the benchmark factor portfolios (for market, size, value, profitability and investment premiums) against, which funds are measured are also gross of such taxes.

In our study, the Chinese Central Bank Bill rate, sourced from the RESSET Database, is used as a proxy for the risk-free interest rate.

As a measure of market return, we use one of the most comprehensive indices of the Chinese stock market - the HuShen 300 Index (the Shanghai Stock Exchange and Shenzhen Stock Exchange largest 300 Stocks Index) [2]. The weekly data of the HuShen 300 Index is taken from the RESSET Database.

The risk factor portfolio for the size premium, small minus big (SMB), is sourced from the RESSET database. SMB is the difference between the weekly returns on a portfolio of small cap stocks and the weekly returns on a portfolio of large cap stocks. The portfolio of small (large) cap stocks consists of the lowest (largest) 30\% of stocks by market capitalization of the main Chinese equity market.

The risk factor portfolio for the value effect, high minus low (HML), is sourced from the RESSET database. HML is the difference between the weekly returns on a portfolio of value stocks and the weekly returns on a portfolio of growth stocks. The portfolio of value (growth) stocks consists of the highest (lowest) $30 \%$ of stocks by book-to-market ratio.

The risk factor portfolio for the profitability premium, robust minus weak (RMW), is sourced from the China Stock Market \& Accounting Research (Database) (CSMAR) database. RMW is the difference of the weekly returns on the highest $30 \%$ profitability stock portfolio and the weekly returns on the lowest $30 \%$ profitability stock portfolio.

The risk factor portfolio for the investment premium, conservative minus aggressive (CMA), is sourced from the CSMAR database. CMA is the difference of the weekly returns 
on the most conservative $30 \%$ stock portfolio and the returns on the most aggressive $30 \%$ stock portfolio.

We also investigate the skill versus luck issues based on conditional performance measures. Five instruments of conditional variables, as discussed in Gao et al. (2017), are sourced as follows: the risk-free interest rate is proxied by the Chinese Central Bank Bill rate, which is sourced from the RESSET Database; the Chinese 10-year Government bond yield taken from DATASTREAM and the Chinese Central Bank Bill rate are used to calculate the slope of the term structure; the dividend yield on the HuShen 300 Index is used as a proxy of the dividend yield of the market factor in this study, which is taken from the RESSET Database; the bond-to-equity ratio is the ratio of the Chinese 10 year Government bond yield to the dividend yield on the HuShen 300 Index; and the difference between the Chinese 10 year corporate bond yield sourced from DATASTREAM and the Chinese 10 year Government bond yield is used to calculate the default spread.

\section{Performance models}

Evaluating fund performance based on raw returns does not consider the levels of risk borne as high raw returns may be associated with high risks. Therefore, in this section, we assess fund performance using well-known risk-adjusted measures [3] to address this issue. We briefly describe the most commonly used performance models in three broad classes, namely, unconditional, conditional beta and conditional alpha-beta models. All models are estimated for the entire set of Chinese open-end equity securities investment funds (788 in this study) and one "best-fit" model within each of the three classes is selected by estimation diagnostics.

\subsection{Unconditional factor models}

These models have factor loadings, which are time invariant.

$$
r_{i, t}=\alpha_{i}+\left[X_{t}\right] \beta_{i}++\varepsilon_{i, t}
$$

where $r_{i, t}$ is the excess return of stock $i$ over the risk-free rate. $X_{t}$ is a matrix of existing risk factors for the market (RmRf), size (SMB), value (HML), profitability (RMW) and investment (CMA) effects, which are well-documented in previous literature, such as Jensen (1968), Fama and French (1993) and Fama and French (2015). The $t$ subscripts denote time. $\alpha_{i}$ measures abnormal return after controlling for the aforementioned five risk factors, and hence, a significant positive $\alpha_{i}$ indicates superior risk-adjusted performance.

\subsection{Conditional beta performance measures}

The above unconditional measures fail to take account of changing market information about the expected returns and risks of individual securities. Ferson and Schadt (1996) allow for the possibility that a fund's factor sensitivities (betas) at time $t$ may be linearly related to lagged public economic information variables as follows:

$$
\beta_{i t}=b_{0 i}+B^{\prime}\left(z_{t}\right)
$$

where $z_{\mathrm{t}}$ represents the vector of deviations of the economic information set $Z_{\mathrm{t}}$ from unconditional means, and hence, $b_{0 i}$ is the unconditional mean of the conditional beta.

Therefore, the conditional beta CAPM gives: 
where $r_{i, t}$ denotes the expected excess return on fund $i$ at time $t$.

The Model in (3) captures the abnormal return when a fund manager dynamically alters portfolio weights and adjusts the fund's risk factor loadings using publicly available information and can be extended to multiple factor models, such as the Fama and French three-factor (1993) and five-factor (2015) models in which the additional factor loadings are each specified as linear functions of an economic information set $Z_{\mathrm{t}}$ and as conditional betas.

\subsection{Conditional alpha-beta models}

The Christopherson et al. (1998) study assumes that alpha (as well as the betas) is a linear function of the instruments in $Z_{\mathrm{t}}$ as follows:

$$
\alpha_{\mathrm{it}}=\alpha_{0 \mathrm{i}}+\mathrm{A}_{\mathrm{i}}^{\prime}\left(z_{\mathrm{t}}\right)
$$

Therefore, the Ferson and Schadt (1996) specification can be extended by substituting Model (4) into Model (3):

$$
\mathrm{r}_{\mathrm{i}, \mathrm{t}}=\alpha_{0 \mathrm{i}}+\mathrm{A}_{\mathrm{i}}^{\prime}\left(\mathrm{z}_{\mathrm{t}-1}\right)+\mathrm{b}_{0 \mathrm{i}}\left(\mathrm{RmRf}_{\mathrm{t}}\right)+\mathrm{B}_{\mathrm{i}}^{\prime}\left(\mathrm{z}_{\mathrm{t}-1} * \mathrm{RmRf}_{\mathrm{t}}\right)+\varepsilon_{\mathrm{i}}
$$

The above conditional alpha-beta approach can also be simply applied to multi-factor models.

Following earlier studies (Ferson and Schadt, 1996; Christopherson et al., 1998), our instruments for publicly available information, $Z_{\mathrm{t}}$, include the lagged level of the risk-free interest rate (the Chinese Central Bank Bill rate in this study), the lagged level of dividend yield on the market factor, a lagged measure of the slope of the term structure, a lagged measure of default spread in the corporate bond market and a lagged ratio of returns on bonds to equity.

\section{Bootstrap methodology}

In a large universe of funds (788 in this study), it is likely that some funds will outperform (underperform) purely due to good (bad) luck rather than good (bad) skill. This question is at the core of the analysis in our paper in the case of the hitherto under-investigated Chinese securities investment fund industry. We use a non-parametric bootstrap procedure to construct a distribution of fund abnormal performance that is within the boundary of luck alone and we calculate how actual estimated performance compares against this distribution.

The bootstrap methodology is implemented in Kosowski et al. (2006) and Cuthbertson et al. (2008). These differ from earlier studies that use bootstrapping in that they use information from all funds in the sample to construct a separate distribution of luck at each point in the cross-section of performance, i.e. for the best fund, second best fund and so on down to the worst fund. In earlier studies, the simulated distribution of performance of, for example, the best fund, uses the information about "luck" as represented only by the bestperforming fund ranked by the ex post data.

The bootstrap procedure evaluates fund performance based on the theory of order statistics. Under the null hypothesis of zero abnormal performance, it does not require the empirical distribution for each fund to be normal, and hence, alpha for each individual fund is allowed to take any distribution. Using the historic fund data, the empirical distribution 
representing the simulated (or luck) distribution for each fund is generated. This distribution takes the luck distributions for all of the different individual funds into consideration as this luck distribution can be different for each fund.

\subsection{Steps in baseline bootstrap procedure[4]}

Consider an ordinary least squares (OLS) estimation of equilibrium returns as follows:

$$
r_{i, t}=\alpha_{i}+\left[X_{t}\right] b_{i}+e_{i, t}
$$

where for each of $\mathrm{n}$ funds $\mathrm{i}=\{1,2, \ldots, \mathrm{n}\}, r_{i, t}$ is a $\left(\mathrm{T}_{\mathrm{i}} * 1\right)$ vector of excess returns over the risk free rate for fund $\mathrm{i}$; $\mathrm{T}_{\mathrm{i}}$ is the number of observations of fund $\mathrm{i} ; X_{t}$ is a $\left(\mathrm{T}^{*} \mathrm{k}\right)$ matrix of observations on $\mathrm{k}$ risk factors; $b_{i}$ is a $\left(\mathrm{k}^{*} 1\right)$ vector of the estimated risk factor loading for fund $\mathrm{i}$; and $e_{i, t}$ is a vector of OLS residuals for fund $\mathrm{i}$. In the baseline bootstrap procedure (Efron and Tibshirani, 1993), only regression residuals are re-sampled as follows: First, for each fund, the performance measurement model is estimated by OLS to estimate the "actual" or unmodified risk-adjusted performance measures, we denote these as $\alpha_{i}$. The vectors of estimated OLS residuals and factor loadings, $e_{i, t}$ and $b_{i}$, are saved as $\left\{b_{i}, e_{i, t}\right\}$. Second, a random sample of regression residuals of size $T_{\mathrm{i}}$ is drawn with replacement from $e_{i, t}$. A series of bootstrapped simulated excess returns for fund $i$ is constructed using the original chronological order of $\mathrm{X}_{\mathrm{t}}$ and the estimated factor loadings, $b_{i}$, in step one, under the null hypothesis of no risk-adjusted performance (i.e. $\alpha_{i}$ is set to zero). We denote these simulated excess returns as $\widetilde{r_{i, t}}$ as follows:

$$
\widetilde{r_{i, t}}=0+\left[X_{t}\right] b_{i}{ }^{\prime}+\widetilde{e_{i, t}}
$$

The above is repeated for all funds. In the next step, a bootstrap estimate of risk-adjusted performance (denoted as $\widetilde{\alpha}_{i}^{(B)}$ ) under the null hypothesis is estimated by re-estimating the performance model using these bootstrapped simulated returns (i.e. $\widetilde{r_{i, t}}$ ). The bootstrapped alpha, $\widetilde{\alpha}_{i}^{(B)}$, measures random sampling variation around zero - as by construction the "true" alpha of the simulated returns is zero. This random sampling variation is taken as a distribution attributable to luck. This simulation process is repeated 1,000 times for each of the funds in our sample. A $\left(n^{*} 1,000\right)$ matrix is constructed for the bootstrap estimates of fund performance in the following form:

$$
\left[\begin{array}{cccc}
{\widetilde{\alpha_{1}}}^{(1)} & {\widetilde{\alpha_{1}}}^{(2)} & \ldots & {\widetilde{\alpha_{1}}}^{(1,000)} \\
{\widetilde{\alpha_{2}}}^{(1)} & {\widetilde{\alpha_{2}}}^{(2)} & \ldots & {\widetilde{\alpha_{2}}}^{(1,000)} \\
\vdots & \vdots & \ddots & \vdots \\
{\widetilde{\alpha_{n}}}^{(1)} & {\widetilde{\alpha_{n}}}^{(2)} & \ldots & {\widetilde{\alpha_{n}}}^{(1,000)}
\end{array}\right]
$$

In the next step, each column of the above bootstrap matrix is sorted from highest to lowest to construct a sorted bootstrap matrix. Therefore, the highest values of simulated alpha $\left(\widetilde{\alpha}_{i}{ }^{(B)}\right)$ from the 1,000 bootstraps for each of the $\mathrm{n}$ funds constitute the first row of this sorted bootstrap matrix, and the second row contains the second highest values of $\widetilde{\alpha}_{i}^{(B)}$ from the 1,000 bootstraps for each fund. The last row contains the lowest values of $\widetilde{\alpha}_{i}{ }^{(B)}$ from the 1,000 bootstraps of each fund.

The next step is to rank the $\mathrm{n}$ funds by $\alpha_{i}$ (actual alpha) from highest to lowest. Therefore, to evaluate whether an individual fund possesses genuine securities selection 
$\mathrm{RAF}$

20,5

280

ability (to beat luck), the actual alpha of this fund is compared against the bootstrap luck distribution at that point in the performance distribution. For example, to investigate whether the performance of the actual top ranked fund is simply attributable to luck, the unmodified highest alpha (i.e. the highest $\alpha_{i}$ ) is compared to the luck distribution of best performance under the null hypothesis of no risk-adjusted performance (i.e. the first row of the sorted bootstrap matrix above). In the case of the worst performing fund, its actual alpha is compared to the last row to evaluate whether its underperformance is due to bad luck alone (or whether the worst performance is worse than bad luck).

The probability (or $p$-value) calculated from the sorted bootstrap matrix above can be used as a statistic to assess whether a fund possesses genuine stock picking skills to beat luck. For the top ranked fund, the percentage of bootstrapped simulated alphas (i.e. $\widetilde{\alpha}_{i}{ }^{(B)}$ ) in the first row of the sorted bootstrap matrix that outnumber the highest actual alpha $\left(\alpha_{i}\right)$ is calculated as an estimate of the probability (denoted by $p$-value) that the top ranked fund performs better than good luck. Operating at a 5\% level of significance, if less than $5 \%$ (i.e. $p$-value $<0.05$ ) of simulated alphas in the first row exceed the highest actual alpha, the best actual performance is suggested to be superior to good luck. Similarly, for the worst performing fund, a $p$-value less than $5 \%$ (i.e. $p$-value $<0.05$ ) indicates that among the bootstrap alphas in the last row of the bootstrap sorted matrix above, less than 50 of the 1,000 are less than the lowest actual (unmodified) alpha of the worst performing fund. This fund represents performance worse than bad luck. Note that this kind of comparison between actual fund alphas and simulated distributions of alpha under the null hypothesis of no securities selection ability can be made at each point or each percentile of the performance distribution (from actual top to bottom ranked funds).

\subsection{The t-statistics of alpha as the measure of performance}

Using alpha to measure fund performance, however, may incur some statistical difficulties. As the alphas of funds with few observations may be estimated with a high standard error, outlier alphas may be observed in the sample. Hence, funds with few observations may disproportionately occupy the extreme tails of the distributions of both the actual and bootstrapped simulated alphas. This is a motivation to introduce the $t$-statistic of alpha as the measure of fund performance. The statistical properties of the bootstrapped $t$-statistic distribution are superior to those of the simulated alpha distribution, as the $t$-statistic scales alpha by its estimated precision (i.e. its standard error). These statistical properties enable the bootstrapped $t$-statistic measure to be more reliable in identifying skilled or informed fund managers, especially who have performed extremely well (badly), i.e. whose performance is in the extreme right (left) end of the performance distribution. These are also the funds in which investors are most interested. As such, the bootstrap analysis in our study principally focuses on the luck distribution of the $t$-statistic of bootstrapped alpha $\left(\right.$ denoted by $\left.t_{\alpha_{i}}\right)[5]$.

\subsection{A restriction to funds with a minimum number of observations}

As discussed above, funds with few observations may widen the extreme tails of the bootstrap distribution, which may increase the hurdle for funds to beat luck. This issue is mitigated by using the $t$-statistic bootstrap measure instead of using bootstrapped alpha directly. The issue may be further mitigated by restricting the analysis to funds with some minimum number of observations. However, there is a potential problem caused by imposing such a restriction, namely, that it may introduce a survivorship bias by excluding short-lived funds that may have been forced to close due to poor performance. As such, as a trade-off between minimizing survivorship bias and minimizing the look-ahead bias, we set 
the minimum number of observations at 104 (2 years) rather than a higher number such as 156 (3 years). However, in robustness tests, we investigate the sensitivity of our results to these restrictions.

\section{Empirical results: relative performance and model selection}

We examine over 50 performance models for the data set of Chinese securities investment funds over the period May 2002 to September 2020. The model estimation results, based on funds with a minimum of 104 observations, are presented in Tables 2-4 where crosssectional (across funds) average statistics for each model are reported. Based on these statistics, the level and distribution of abnormal return, the significance of factor loadings, model selection metrics and normality and serial correlation characteristics are examined. A single "best-fit model" is selected from each of the three model classes, namely, unconditional models, conditional beta models and conditional alpha-beta models.

\subsection{Unconditional models of performance}

Table 2 presents the estimation results of the unconditional models, which include the CAPM (Model 1), the Fama and French three-factor model (Model 2) and the Fama-French five-factor model (Model 3)[6], as well as the unconditional market timing models of Treynor-Mazuy model (Model 4) and Henriksson-Merton model (Model 5). The results across all unconditional models suggest the average underperformance of Chinese funds

\begin{tabular}{llccccc}
\hline & & 1 & 2 & 3 & 4 & 5 \\
\hline Model & & CAPM & FF3 & FF5 & TM & HM \\
Regression coefficients & & & & & & \\
Average alpha (percent per week) & & -0.001 & -0.005 & -0.026 & 0.074 & 0.160 \\
$t$-statistic & & 1.152 & 1.1291 & 1.011 & 1.417 & 1.413 \\
Standard deviation of alpha & & 0.002 & 0.002 & 0.001 & 0.002 & 0.003 \\
& & & & & & \\
T-statistics of unconditional betas & & & & & & \\
& RmRf & 19.782 & 17.301 & 17.786 & 19.453 & 14.030 \\
& SMB & & 3.111 & 2.084 & &
\end{tabular}

$T$-statistics of market timing measures
Treynor-Mazuy

Henriksson-Merton

$$
\begin{aligned}
& \mathrm{r}_{\mathrm{mt}}^{2} \\
& {\left[\mathrm{r}_{\mathrm{mt}}\right]^{+}}
\end{aligned}
$$

$\begin{array}{lllll} & & & 1.301 & \\ & & & & 1.237 \\ & & & & \\ 0.724 & 0.788 & 0.798 & 0.728 & 0.727 \\ -8.222 & -8.468 & -8.470 & -8.218 & -8.213 \\ 89.754 & 91.803 & 91.393 & 89.959 & 90.369 \\ 12.500 & 22.541 & 19.057 & 13.320 & 13.525 \\ 19.672 & 26.230 & 27.049 & 20.082 & 21.926\end{array}$

Model selection criteria

Adjusted $R^{2}$

$\mathrm{SIC}$

Rejection of normality ( $\%$ of funds)

LM(1) statistic ( $\%$ of funds)

$\operatorname{LM}(6)$ statistic ( $\%$ of funds)

Notes: Table 2 presents results from the estimation of the unconditional performance models using all securities investment funds. Average alphas are reported for each model (\% per week). All figures shown are cross-sectional averages. Funds with at least 104 observations are examined

\section{Chinese securities investment funds}


$\mathrm{RAF}$

20,5

282

while this underperformance is statistically insignificant at $5 \%$. In addition, when more risk factors are used to adjust fund performance, a lower value of alpha may be expected.

The $t$-statistics across all unconditional models suggest consistent findings regarding the significance of factor loadings, namely, the market, size and value risk factors determine the cross-sectional variation in fund returns statistically significantly. In the Fama and French five-factor model (Model 3), all funds show a statistically significant value on the market risk factor while $44 \%$ and $62.5 \%$ of funds have a significant $t$-statistic on the size and value risk factor loadings, respectively. The profitability and investment risk factors are insignificant on average while they explain the cross-sectional variation in fund returns statistically significantly for around $28 \%$ of funds.

In terms of the market timing specifications (Models 4 and 5), both the Treynor-Mazuy (1966) model (Model 4) and the Henriksson-Merton (1981) model (Model 5) produce similar market timing results: there is no evidence of market timing ability among fund managers on average, as the cross-sectional average alpha is positive but still statistically insignificant on average.

\subsection{Conditional beta models of performance}

A representative selection[7] of the estimation results of the conditional beta specifications are reported in Table 3 . The conclusions regarding alpha and the distribution of alpha for conditional beta measures are very similar to those in Table 2 from unconditional models. According to the results from all conditional beta models, negative values of average abnormal return indicate that Chinese securities investment fund managers underperformed on average though alpha from all models is not statistically significantly different from zero at the $5 \%$ significance level.

Our findings in relation to the significance of risk factor loadings are broadly similar to those from unconditional models. All conditional beta models consistently indicate that the market, size and value risk factors are statistically significant determinants of the crosssectional variation in fund returns. Among all conditional beta models, the public economic information instruments are statistically insignificant at the $5 \%$ significance level.

\subsection{Conditional alpha-beta models of performance}

Table 4 shows the estimation results of the conditional alpha-beta measures. The relative performance measure remains negative and statistically insignificant based on all conditional alpha-beta models. Similarly, Table 5 also strongly demonstrates that the full sets of conditional public economic information variables are statistically insignificant on average.

The findings of insignificance among the conditioning variables from both conditional beta and alpha-beta models indicate that fund managers do not (dynamically) adjust the risk factor loadings (or at least do not do so successfully) in response to the full set of public economic information instruments examined in our study.

\subsection{Model selection diagnostics}

The cross-sectional average (across funds) Schwartz Information Criterion (SIC) for each model, which is used as the key metric to select the "best-fit" model from each class, is presented in Tables 2-4. The SIC trades off a reduction in a model's residual sum of squares for a parsimonious "best-fit" model. The model with the lowest value of SIC in each class is suggested as the "best-fit" model. The unconditional Fama and French five factor model (Model 3) generates the lowest SIC value of -8.470 among all models, and hence, it is selected as the "best-fit" performance measure for all three categories. Model 3, Model 10 (a 


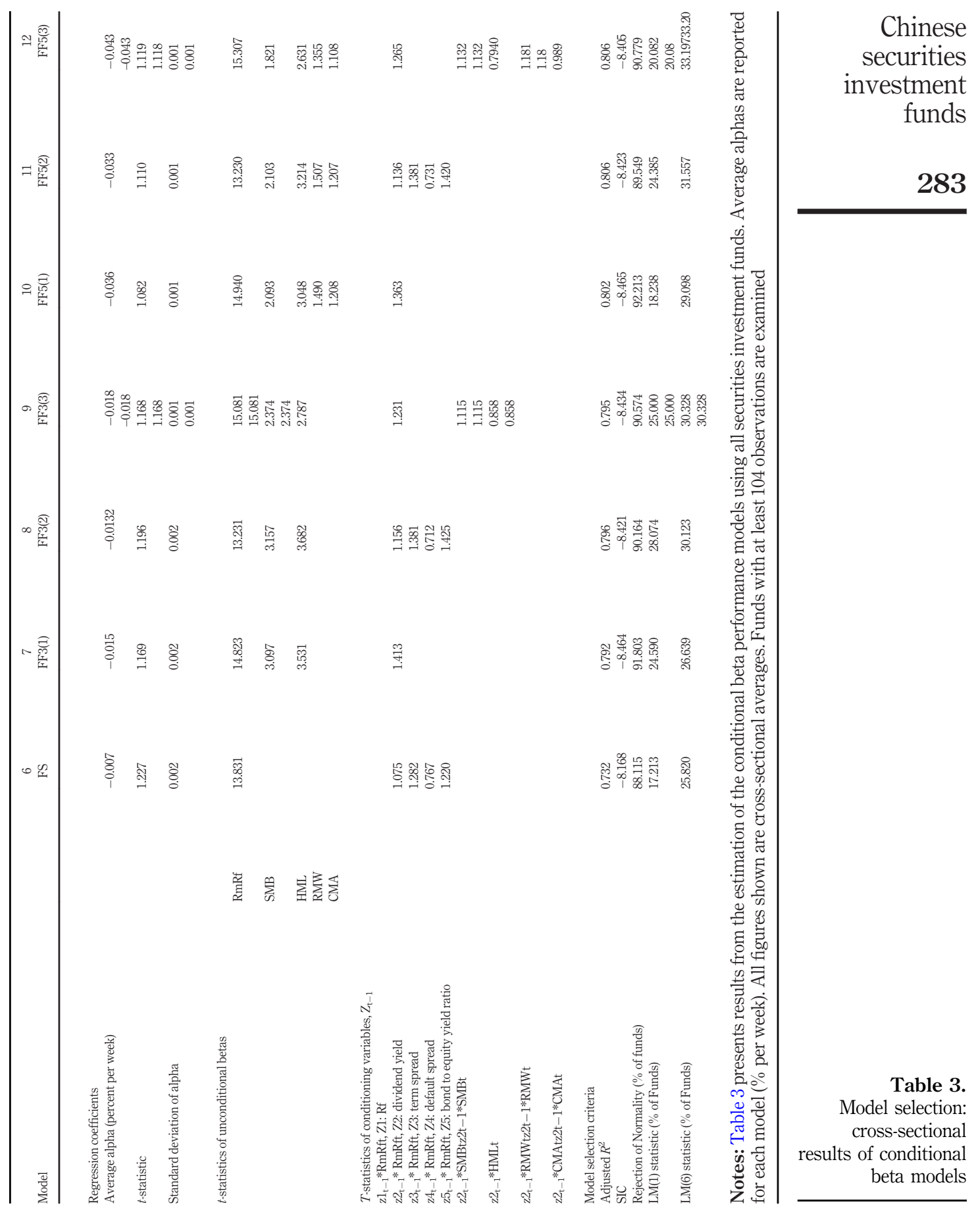




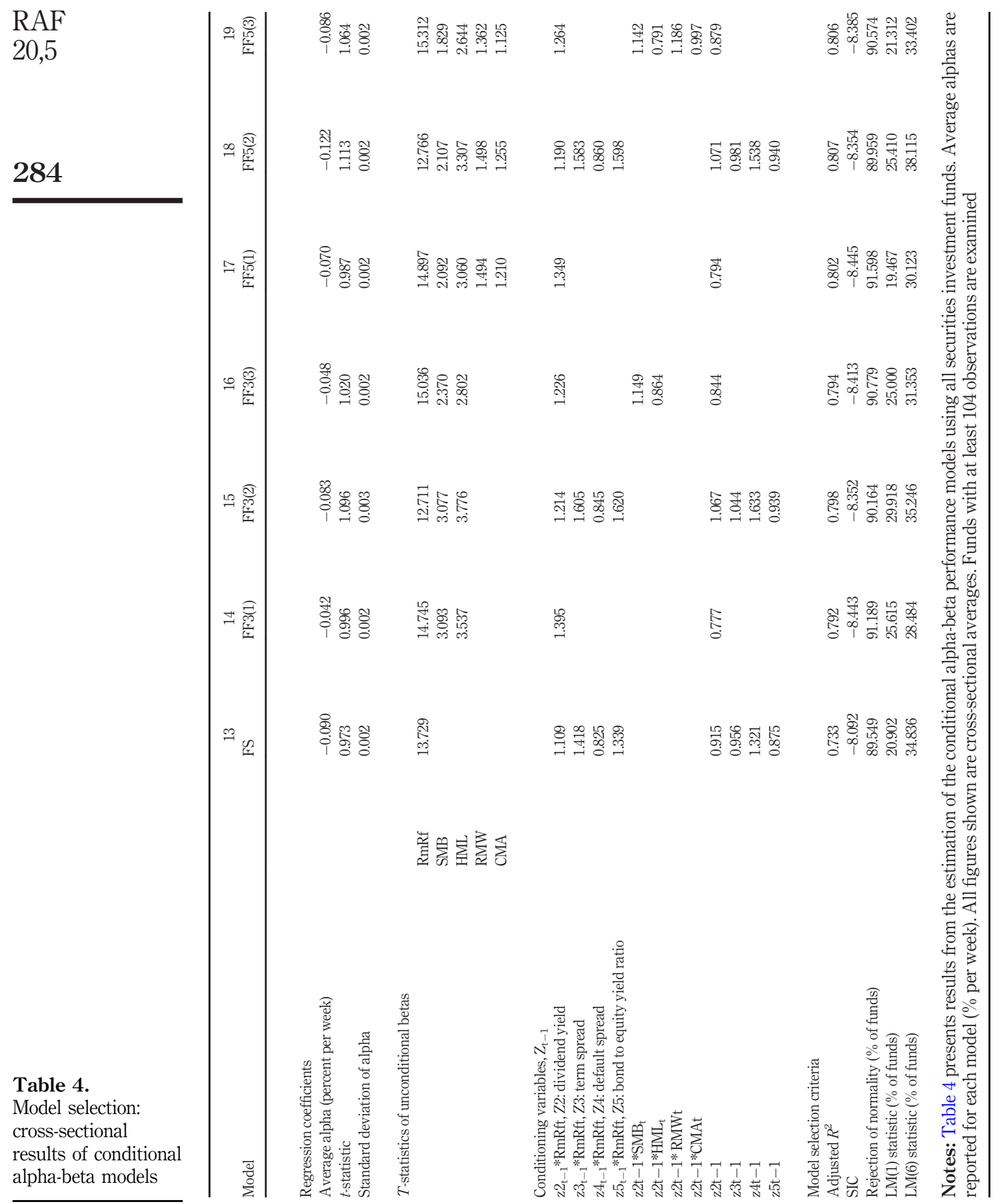


Fama French five-factor-based conditional beta model) and Model 17 (a Fama French fivefactor-based conditional alpha-beta model) are selected within the classes of unconditional, conditional beta and conditional alpha-beta models, respectively.

\section{Chinese securities investment funds}

\subsection{Non-normality and significant alphas}

As discussed in Section 1, analysis of fund performance based on the aforementioned factor models give rise to two issues - the requirement of normality and difficulty in distinguishing skill from luck in fund manager's stock picking ability. Based on the empirical evidence from Tables 2-4, there exists a high degree of non-normality in the residuals from the performance models for around $90 \%$ of Chinese securities investment funds examined, and hence, alphas from these model estimations may not satisfy the requirement of a normal distribution. Therefore, we use the bootstrap methodology in Kosowski et al. (2006), which does not require fund returns to be normally distributed.

Regarding the second issue, although the Chinese fund industry displays insignificant abnormal performance on average, a small portion of funds (around 3\%) are found to yield significant positive alphas while around $10 \%$ of them yield significant negative alphas. Our findings regarding relative performance based on conventional statistical measures (i.e. factor models) are consistent with previous studies (Hendricks et al., 1993; Carhart, 1997; Christopherson et al., 1998; Blake and Timmermann, 1998; Quigley and Sinquefield, 2000; Fletcher and Forbes, 2002; Cuthbertson et al., 2008; Gao et al., 2020).

However, it is possible that some funds earn significant positive (negative) abnormal returns simply due to good (bad) luck. Therefore, we use the bootstrap methodology, which directly addresses the issue of "skill versus luck" and the empirical results are presented and discussed in the next section.

\section{Empirical results: bootstrap analysis}

Previous literature on the USA and the UK markets suggests only a small proportion of mutual fund managers exhibit superior stock selection ability based on bootstrap approaches (Kosowski et al., 2006; Cuthbertson et al., 2008). A possible explanation is that as developed industries, market efficiencies lead to few opportunities to earn abnormal returns in the USA and the UK. The Chinese fund market, however, as a newer market, may be less efficient, and hence, possible market inefficiencies may result in more skilled and informed fund managers. We present the main findings from applying the bootstrap procedure in this section to answer the above question. The analysis is restricted to funds with a minimum of 104 observations, leaving a sample of 488 funds. We later report on the sensitivity of our findings to this restriction.

Based on the statistical significance of the individual parameters and the SIC in Section 5, within the class of unconditional models, the unconditional Fama and French (2015) fivefactor model is considered as the best-fit model as follows:

$$
\mathrm{r}_{\mathrm{i}, \mathrm{t}}=\alpha_{\mathrm{i}}+\beta_{1 \mathrm{i}} \mathrm{RmRf}_{\mathrm{t}}+\beta_{2 \mathrm{i}}(\mathrm{SMB})_{\mathrm{t}}+\beta_{3 \mathrm{i}}(\mathrm{HML})_{\mathrm{t}}+\beta_{4 \mathrm{i}}(\mathrm{RMW})_{\mathrm{t}}+\beta_{5 \mathrm{i}}(\mathrm{CMA})_{\mathrm{t}}+\varepsilon_{\mathrm{i}, \mathrm{t}}
$$

where $(\mathrm{SMB})_{\mathrm{t}},(\mathrm{HML})_{\mathrm{t}},(\mathrm{RMW})_{\mathrm{t}}$ and $(\mathrm{CMA})_{\mathrm{t}}$ are the size, value, profitability and investment risk factors, respectively.

In Section 5, we find that the conditional beta Fama and French five-factor model where the market risk factor loading is conditional on a signal provided by the market dividend yield is the best model among conditional beta models as follows: 


$$
\begin{aligned}
\mathrm{r}_{\mathrm{i}, \mathrm{t}}= & \alpha_{\mathrm{i}}+\beta_{1 \mathrm{i}} \mathrm{RmRf}_{\mathrm{t}}+\beta_{2 \mathrm{i}}(\mathrm{SMB})_{\mathrm{t}}+\beta_{3 \mathrm{i}}(\mathrm{HML})_{\mathrm{t}}+\beta_{4 \mathrm{i}}(\mathrm{RMW})_{\mathrm{t}}+\beta_{5 \mathrm{i}}(\mathrm{CMA})_{\mathrm{t}} \\
& +\beta_{6 \mathrm{i}}\left[\mathrm{Z} 2_{\mathrm{t}-1} \mathrm{RmRf}_{\mathrm{t}}\right]+\varepsilon_{\mathrm{i}, \mathrm{t}}
\end{aligned}
$$

where $Z 2_{\mathrm{t}-1}$ is the lagged level of dividend yield on the market factor.

Among conditional alpha-beta models, we find that a Fama and French five-factor model, which allows alpha, as well as the market factor loading to time-vary conditional on the market dividend yield, is the best fit model as follows:

$$
\begin{aligned}
\mathrm{r}_{\mathrm{i}, \mathrm{t}}= & \alpha_{\mathrm{i}}+\mathrm{A}_{\mathrm{i}} Z_{\mathrm{t}-1}+\beta_{1 \mathrm{i}} \mathrm{RmRf}_{\mathrm{t}}+\beta_{2 \mathrm{i}}(\mathrm{SMB})_{\mathrm{t}}+\beta_{3 \mathrm{i}}(\mathrm{HML})_{\mathrm{t}}+\beta_{4 \mathrm{i}}(\mathrm{RMW})_{\mathrm{t}} \\
& +\beta_{5 \mathrm{i}}(\mathrm{CMA})_{\mathrm{t}}+\beta_{6 \mathrm{i}}\left[Z_{\mathrm{t}-1} \mathrm{RmRf}_{\mathrm{t}}\right]+\varepsilon_{\mathrm{i}, \mathrm{t}}
\end{aligned}
$$

We select these unconditional and conditional models for the bootstrap analysis in our study. However, as reported in Section 5, the unconditional Fama-French five factor model is the best model overall, and hence, we focus our discussion on the empirical results from this model.

The bootstrap performance statistics for the full sample of Chinese equity securities investment funds are reported in Table 5. Panels A, B and C present the bootstrap results for the Fama-French-based unconditional, conditional beta and conditional alpha-beta five-factor models as described above, respectively. Row 1 in each panel of Table 5 shows the actual alpha, which is measured weekly, sorted from lowest to highest (left to right). The second row represents the corresponding $t$-statistic of the alpha in Row 1 . Row 3 reports the $t$-statistics of alpha, which are sorted from lowest to highest. As discussed previously, the $t$-statistic has superior statistical properties, as it scales the alpha measure by its standard error and mitigates the probability of observing outliers (particularly in the extreme tails of the performance distribution). Therefore, our study adopts the $t$-statistic of alpha as the measure of fund performance. Row 4 presents the bootstrap $p$-values of the $t$-statistic in Row 3 based on the bootstrap procedure described in detail in the previous section. Row 5 reports the number of fund return observations.

As indicated in Table 5 Panel A, the top ranked fund by actual alpha from the unconditional Fama-French five-factor model earns an abnormal return of $0.44 \%$ per week (25.65\% annually) with a $t$-statistic of 3.390 . This is also the best ranked fund by the $t$ statistic. This fund has a bootstrap $p$-value (of the $t$-statistic) of 0.25 . This suggests that under the null hypothesis of no stock picking skills, $25 \%$ of the highest simulated $t$-statistics from the 1,000 bootstrap simulations exceed 3.390. As discussed above, a $p$-value greater than 0.05 indicates the null hypothesis of no stock selection ability cannot be rejected. Therefore, the top ranked fund achieves a level of performance that is within the boundary of chance or good luck at the $5 \%$ significance level.

The empirical results in Panel A for the entire right tail of the performance distribution indicate that we cannot reject the hypothesis that all positive alpha funds do not possess genuine stock selection ability at a $5 \%$ significance level - all positive $t$-statistics of alpha of these funds are not greater than what could be attributable to good luck at the 5\% significance level. The conclusions regarding outperforming funds are broadly consistent with the conclusions reached by the bootstrap analysis from both conditional beta and condition alpha-beta Fama-French models - none of the funds that earn abnormal positive returns possess genuine stock selection skills at the $5 \%$ significance level.

In terms of the left tail of the performance distribution (i.e. negative alpha funds), the evidence from Panel A shows that the worst fund ranked by actual alpha yields a negative abnormal return of $-0.54 \%$ per week ( $-24.54 \%$ annually) with a $t$-statistic of -4.807 . This 


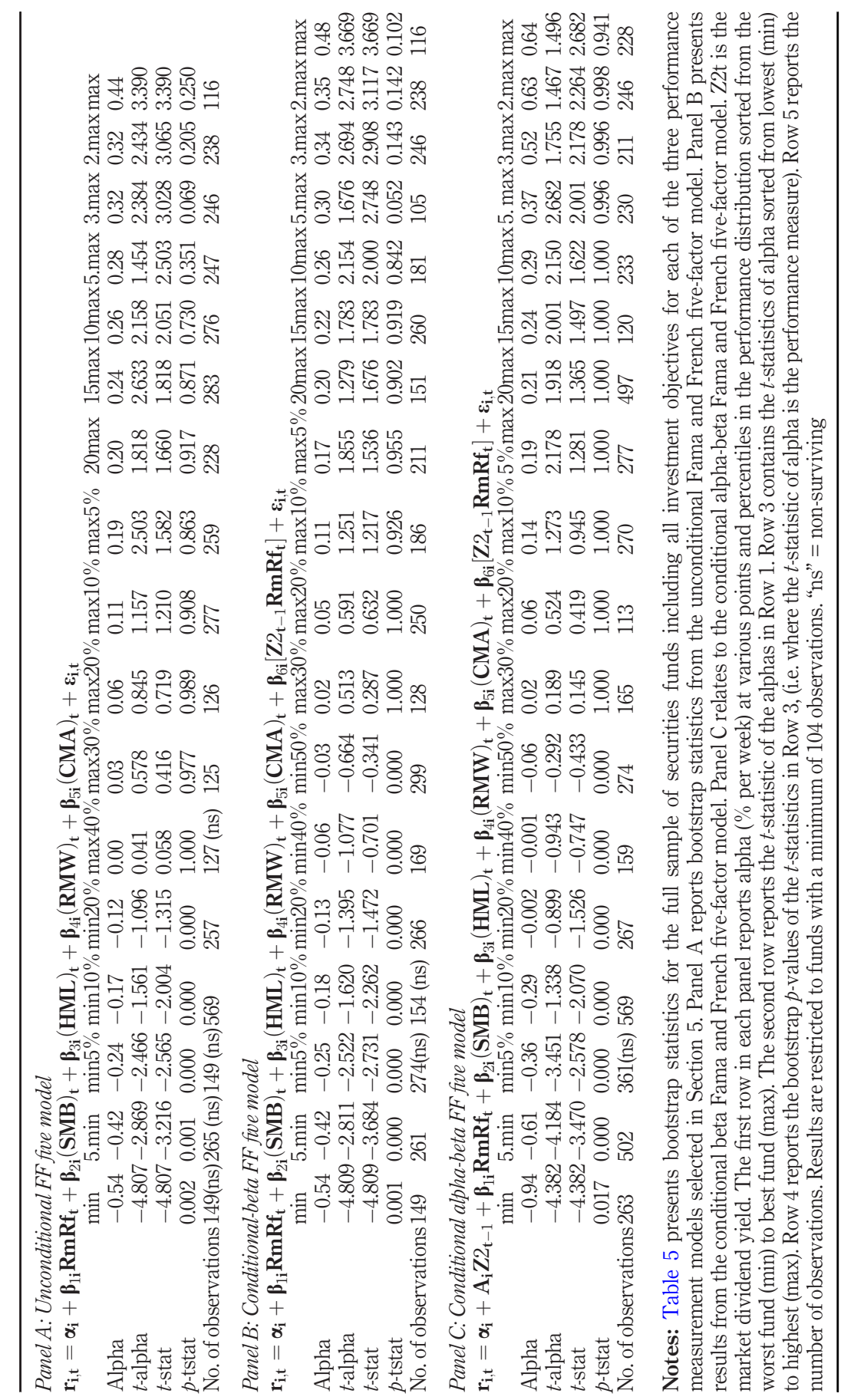


$\mathrm{RAF}$

20,5

\section{8}

Figure 1.

Kernel density estimates of the actual and bootstrap distribution of $t$ statistics fund is also the worst ranked fund by the $t$-statistic of alpha. The bootstrap $p$-value of the $t$ statistic of that fund is 0.002 , which means that under the null hypothesis of zero abnormal performance, $0.2 \%$ of the worst bootstrapped $t$-statistics from 1,000 simulations across all funds are less than -4.807 . Operating at a $5 \%$ level of significance, the worst ranked fund is suggested to perform better than only $0.2 \%$ of observations at the bottom point of the performance scale, which is represented by random sampling variation around zero. Hence, it is concluded that the worst fund produces "genuine" inferior performance worse than bad luck. As indicated by the left side of Panel A, most poor performing funds yield negative alphas due to bad skills rather the bad luck while in results not shown in the table (but illustrated in Figure 1) some funds distributed around the mid-lower segment (around the worst 40th to 50th percentiles) of the performance distribution do not produce genuine underperformance worse than bad luck. Panels $\mathrm{C}$ and $\mathrm{D}$ (conditional beta and alpha-beta FF models) report very similar results in respect of poor performance - unskilled fund managers perform worse than bad luck.

Our findings based on weekly returns and unconditional and conditional Fama French five-factor models are broadly consistent with the conclusions reached in the Yang and Liu (2017) study, which also applies the bootstrap methodology but based on the Carhart fourfactor model to Chinese monthly data[8]. No genuine stock selection ability among winning funds is found regarding both monthly and weekly fund performance. On the left side, the bottom ranked funds possess genuine bad skills.

However, as indicated in Section 5, the conditional models offer little or no additional explanatory power over the Fama-French five-factor model. Accordingly, the unconditional Fama-French five-factor model is selected as the benchmark performance model here, and further bootstrap analysis is discussed based on this model.

Figure 1 plots Kernel density estimates of the distributions of the $t$-statistics of alpha in the actual data and the bootstrap distribution (based on unconditional Fama-French model). The solid line illustrates the distribution of simulated $t$-statistics as the random variation or dispersion in the $t$-statistics of alpha around a "true" value of zero. The dashed line provides

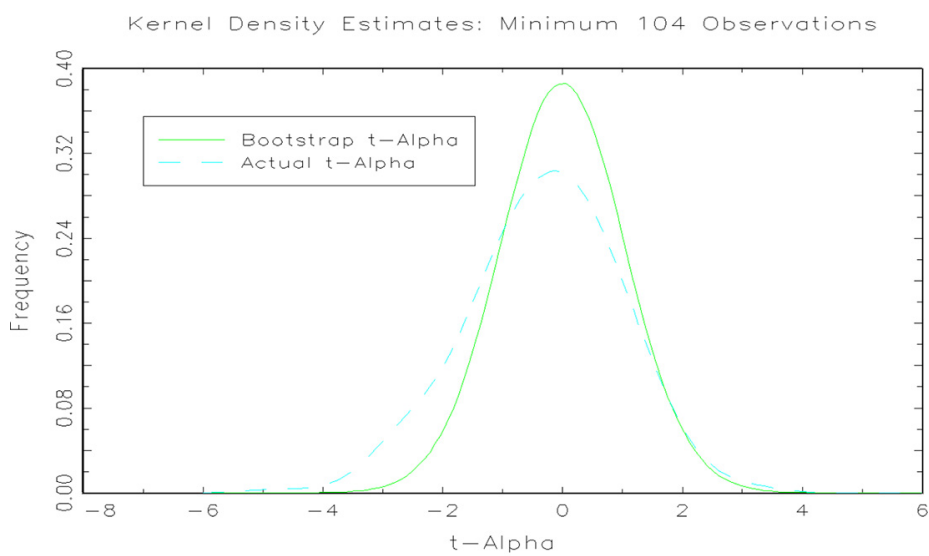

Notes: Figure 1 presents Kernel densities of the actual and bootstrap distributions of the t-statistics of alpha from the unconditional FamaFrench five factor model over the full sample of securities investment funds. t-statistics are Newey-West adjusted. Funds with a minimum of 104 observations are used 
a picture of the distribution of the actual (unmodified) $t$-statistics. Hence, Figure 1 provides further insight into actual fund performance relative to luck by comparing the shapes of the two distributions. As the left of the actual distribution lies beyond the bootstrap distribution, low ranking funds may attribute their poor performance to unskilled fund managers rather than bad luck. However, Figure 1 also indicates that there are some midranking funds with negative alpha that perform better than bad luck.

Figures 2(a) and 2(b) illustrate histograms of the bootstrapped $t$-statistic of alpha from the unconditional Fama-French model at selected points in the upper and lower end of the performance distribution, respectively. The histogram of the highest bootstrap $t$-statistics across funds from each one of the 1,000 simulations under the null hypothesis of zero abnormal performance is represented by the upper left panel in Figure 2(a). The upper right panel shows the 1,000 99th percentile bootstrap $t$-statistics and so on. An almost mirror image of this is represented in Figure 2(b) for the lower end of the performance scale. Regarding the upper end of the performance distribution [shown in Figure 2(a)], it is evident that the bootstrapped $t$-statistics at the top end of the performance distribution (i.e. best and 99th percentile) exhibit greater nonnormality and higher variance compared to the simulated $t$-statistics at points closer to the center of the performance scale (i.e. 95th and 90th percentiles). It is similar at the lower end of the performance scale [shown in Figure 2(b)]: the histograms closer to the center of the performance distribution exhibit a lower variance and more closely approximate normality while histograms at extreme ends are highly non-normally distributed and have a relatively higher variance. As discussed in Section 5 and indicated by Gao et al. (2020), the regression residuals of the top and bottom ranked funds also exhibit greater non-normality and higher variance than residuals of mid-ranked funds. Inferences regarding fund performance, however, based on "conventional" statistical measures may induce bias as they require restrictive assumptions around normality. The bootstrap analysis, however, does not assess abnormal performance relying on the normality assumptions. Therefore, more accurate conclusions can be drawn throughout the bootstrap analysis in respect of the statistical significance of individual fund performance, particularly at the extreme ends of the performance distribution in which investors are more interested.

Our findings presented are different from those for the USA and the UK mutual fund industries. Using the $t$-statistic as the performance measure, genuine stock selection ability is found to be much more prevalent among UK equity mutual funds - some top ranked funds can deliver outperformance due to "true" stock picking skills rather than luck (Cuthbertson et al., 2008). The evidence of skilled fund managers in the Kosowski et al. (2006) US study, however, is slightly more widespread than that of skill in the Cuthbertson et al. (2008) study - their findings are in support of genuine positive abnormal performance among many top ranked funds. Regarding poor performers, the conclusions, which suggest poor performance is attributable to bad skill, however, are consistent with the conclusions in respect of USA and UK mutual funds (Kosowski et al., 2006; Cuthbertson et al., 2008).

\subsection{Sensitivity of findings to alternative minimum fund histories}

We also conduct the bootstrap procedure (based on the unconditional Fama-French fivefactor model) for a range of alternative minimum observation restrictions to examine the sensitivity of findings to different minimum fund histories. Kernel density plots of the actual and simulated distribution of the $t$-statistics for the alternative minimum observation requirements from 208, 156, 104 to 52 are illustrated in Figure 4[9]. From Figure 4 it is clear that the left extreme tail of the actual distributions (dashed line) of $t$-statistics lies beyond the bootstrap performance distribution for all the alternative minimum fund histories, suggesting genuine negative abnormal performance among bottom-ranked funds. 


\begin{tabular}{l} 
RAF \\
20,5 \\
290 \\
\hline
\end{tabular}
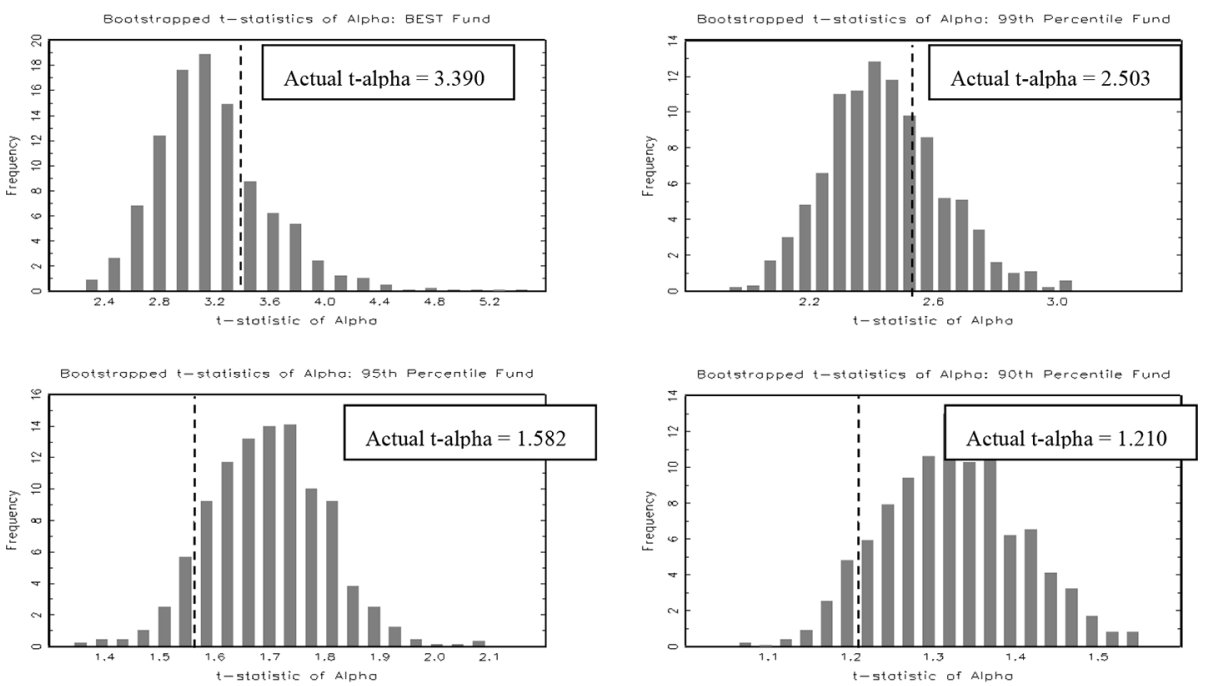

(a)
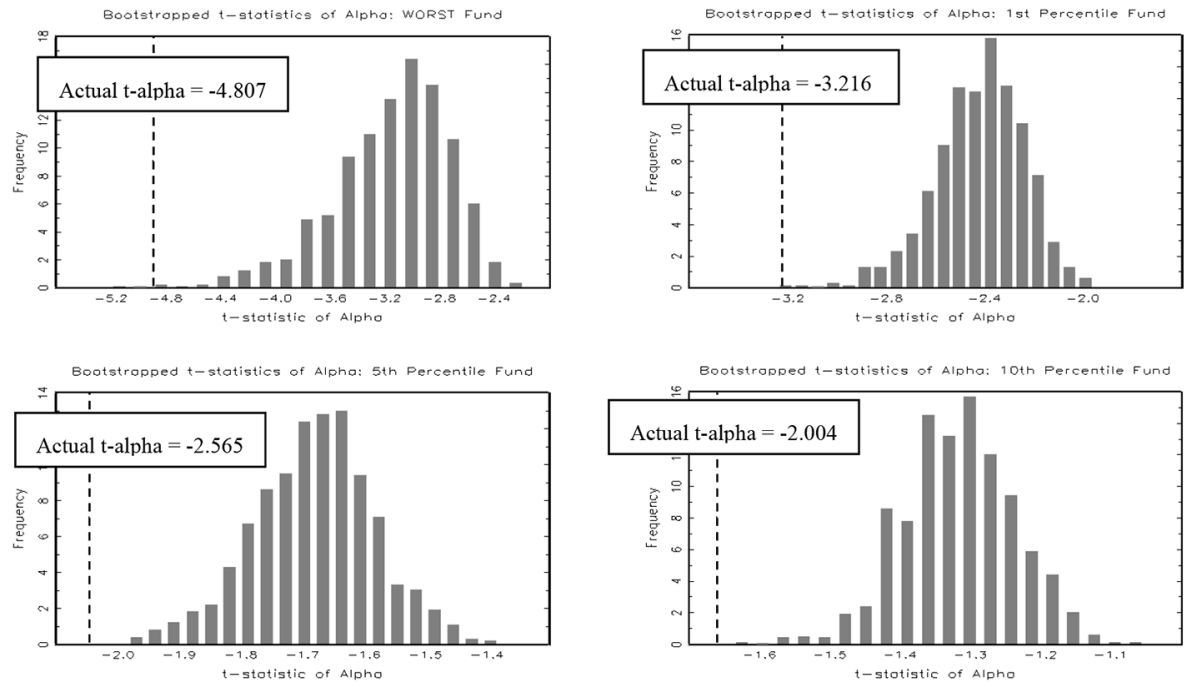

(b)

Figure 2.

Histograms of Bootstrap t-statistics
Notes: (a) Upper End of the Distribution; (b) lower End of the Distribution; Figure 2(a) shows histograms of the bootstrap t-statistics of alpha from the estimation of the unconditional FF five-factor model at various points in the upper end of the cross-sectional performance distribution. The actual $t$-statistics at each ranking is indicated by the vertical dashed line

\subsection{Bootstrap results of sub-periods}

As further analysis and robustness test, we examine the performance of Chinese funds separately for the sub-periods of 2003-2006, 2007-2014 and 2015-2020. The results are 


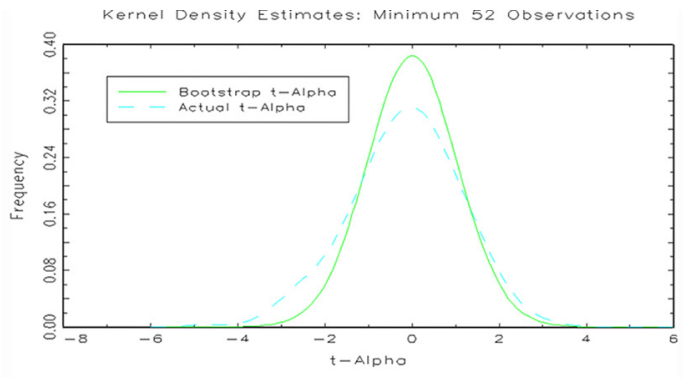

Chinese securities investment funds
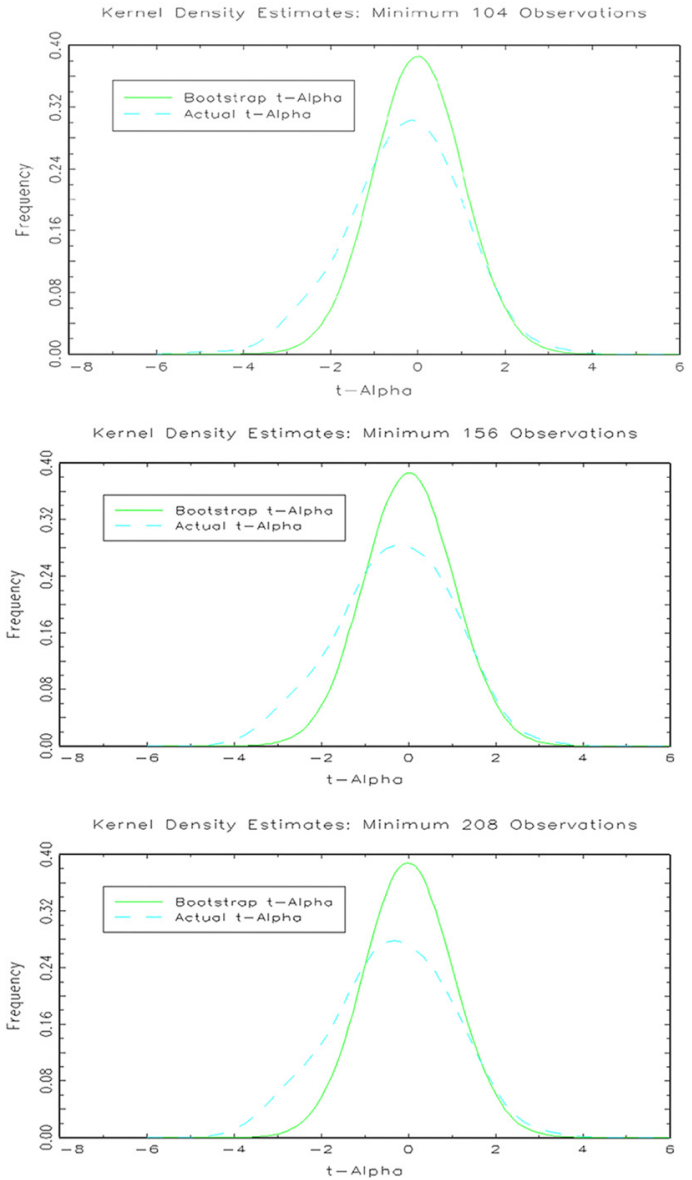

Notes: Figure 3 presents Kernel densities of the actual and bootstrap distributions of the t-statistics of alpha for funds with a minimum of 52,104, 156 and 208 observations using the unconditional FamaFrench 5 factor model. T-statistics are Newey-West adjusted

Figure 3.

Kernel Density Estimates of the Actual and Bootstrap Distribution of tstatistics Alternative Minimum Fund Histories 
presented in Table 6[10]. Similar to the results of the entire period, overall, no significant evidence is found in support of genuine positive abnormal performance among top ranked funds across sub-periods while poor performance is found to be attributable to bad luck during the period of 2007-2014. After 2014, however, the underperformance of most bottom ranked funds is due to fund manager's bad skills rather than bad luck. Regarding the upper end of the performance distribution, however, the alphas in 2007-2014 are much lower than the alphas in 2015-2020 while the sub-sample of 2007-2014 displays the highest bootstrap $p$-values as well. This suggests that Chinese equity funds (particularly top ranked funds) performed worse during 2007-2014 compared with the performance during 2015-2020. A possible explanation is that the Chinese securities investment equity fund industry was influenced by the global financial crisis of 2007-2008, and hence, funds produced inferior performance with the period in the run up to and aftermath of the global financial crisis.

\subsection{Extensions of the bootstrap methodology}

The bootstrap procedure outlined in the methodology section is the "baseline" methodology. However, it can also be extended by incorporating additional features of fund returns, such as serial correlation and heteroscedasticity among fund regression residuals. The inferences based on these extensions of the baseline bootstrap methodology are very similar in respect of skill versus luck in fund performance[11]. This indicates that conclusions from the baseline bootstrap procedure are robust in relation to serial correlation and heteroscedasticity adjustments.

\section{Conclusions}

Our paper investigates the role of skill versus luck in the performance of the Chinese securities investment fund industry using a non-parametric bootstrap methodology and makes several contributions to the literature. First, we examine a wide range (over 50) of risk-adjusted performance models, which accounts for both unconditional and conditional risk factors. We also control for the profitability and investment risk factors in Fama and French (2015), which are not considered in past papers, such as Zhou and Shi (2004), Xiao and Yang (2005), Luo (2011), Gao et al. (2020), Xu and Liu (2009), Yang and Liu (2017) and Yan (2020). Second, we select the "best-fit" model across all risk-adjusted models examined, as well as a single "best-fit" model from each of the three classes (i.e. unconditional, conditional beta and conditional alpha-beta models). We then implement the bootstrap methodology to address the issue of non-normality and to investigate the role of "luck" in fund performance. Therefore, our bootstrap analysis, applied to the best-fit models, is more precise and robust compared to inferences based on conventional $t$-statistics. Third, we reduce the possibility that findings may be sample-period specific or may be a survivor (upward) biased because our sample period, which covers periods of changing market conditions and major market/industry events, to our knowledge, is the longest among studies on the Chinese fund industry; and we include as many non-surviving funds as current data sources allow over the sample period. Fourth, we consider further analysis based on sub-periods and compare fund performance in different market conditions to provide more implications to investors and practitioners. Fifth, we carry out extensive robustness checks and show that the findings are robust in relation to different minimum fund histories, serial correlation and heteroscedasticity adjustments. Sixth, we use higher frequency weekly data to improve statistical estimation and inferences - a difficulty with much of the extant work in Chinese securities investment funds.

Our findings show that at the upper end of the performance distribution, the analysis in our study fails to reject the null hypothesis that outperforming funds may be merely lucky. All the funds which yield a significant positive alpha are within the boundaries of 


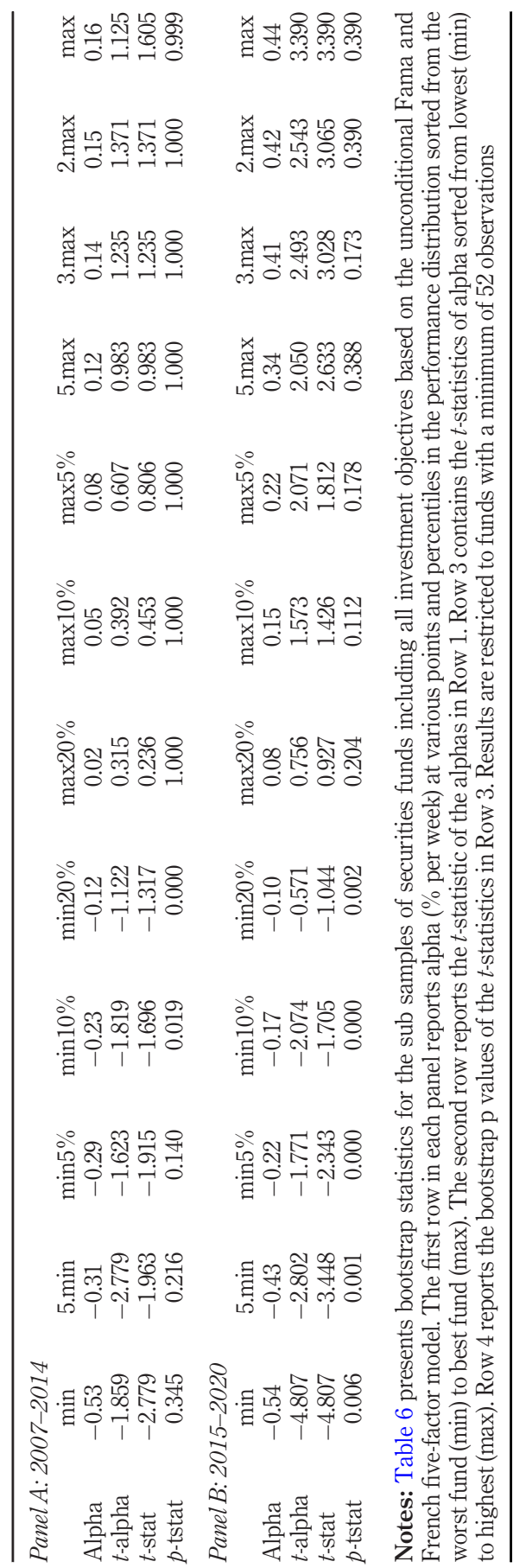

Chinese securities investment funds

293

Table 6.

Statistical significance of Chinese securities investment fund performance 
performance that may be explained by chance - the evidence does not support the existence of "genuine" skilled or informed fund managers.

Regarding the negative end of the performance scale, the bootstrap findings indicate that a large number of funds with negative abnormal returns produce genuine inferior poor performance. However, some funds which are distributed around the mid-lower segment (the worst 40th to 50th percentiles) of the performance distribution attribute their underperformance to bad luck, not a bad skill.

The above results are robust with respect to alternative performance models, different minimum fund histories and a number of extensions to the baseline bootstrap approach, which involves different bootstrap re-sampling methods that retain valuable information on the fund return data generating process.

Overall, our findings regarding the lower end of the performance distribution are broad in line with the findings from previous Chinese fund industry studies (Xu and Liu, 2009; Yang and Liu, 2017; Chen and Chen, 2017; Yan, 2020) and from the USA and the UK studies (Kosowski et al., 2006; Cuthbertson et al., 2008). In relation to the upper end of the performance distribution, however, our findings are quite different from those in Kosowski et al. (2006) and Cuthbertson et al. (2008) as the evidence from their studies shows that top ranked USA and UK mutual funds exhibit good performance attributable to genuine stock selection skills.

The average poor performance of the Chinese equity securities investment fund industry may be caused by the following: as an emerging market, the history of the Chinese fund industry is much shorter than the USA and UK fund industries, and hence, fewer experienced and skilled fund managers may exist in the Chinese fund industry. In addition, many experienced fund managers have left the Chinese fund industry since the financial crisis (Yang and Liu, 2017). Compared with developed stock markets, such as the USA and the UK, there are more individual investors in the Chinese stock market (Feng, 2015; Yang and Liu, 2017). Their irrational behaviour may influence the Chinese stock market and further influence the Chinese equity fund market. The Chinese fund managers are found to make transactions more frequently (Yang and Liu (2017), which lead to a large amount of transaction costs. As indicated in Grinblatt and Titman (1986), Wermers (2000) and Fama and French (2010) management fees and transition costs erode fund performance.

Regarding the active fund management industry as a whole, we find that the performance of top ranked funds with positive abnormal performance is attributable to "good luck" not "good skill" while the negative abnormal performance of bottom funds is mainly due to "bad skill." Therefore, sensible advice for most Chinese equity investors would be against trying to "pick winners funds" among Chinese securities investment funds but it would be recommended to avoid holding "losers." At the present time investors should consider other types of funds, such as index/tracker funds with lower transactions. In addition, less risk-averse investors may consider Chinese hedge funds (Zhao, 2012) or exchange-traded funds (Han, 2012).

\section{Notes}

1. The RESSET Database, established in 2006, is one of the most widely used databases reporting Chinese financial data. It works with many universities including Tsinghua University, Beijing University and the Massachusetts Institute of Technology and provides professional Chinese financial data to over 500 large financial institutions (e.g. China International Capital Corporation Limited, China International Trust Investment Corporation (CITIC) Securities, etc.). The RESSET database has been widely used in academic literature, e.g. Calomiris et al. (2010).

2. The index is comprising 300 common stocks, which, in turn, comprise around $60 \%$ of the market capitalization of all listed stocks on the Shanghai Stock Exchange and Shenzhen Stock Exchange. It is a value-weighted mean of the 300 common stocks and is available as both an index of price 
and an index of total return. We use the latter as it incorporates reinvested dividends, and hence, is comparable with the securities investment fund total returns.

3. The measures include Jensen (1968), Fama and French (1993, 2015), Treynor and Mazuy (1966), Merton and Henriksson (1981), 1Ferson and Schadt (996) and Christopherson et al. (1998).

4. Efron and Tibshirani (1993) discuss bootstrap methodologies and their properties in detail.

5. More discussion of estimation error in alpha is provided by Mamaysky et al. (2004).

6. We did not examine the Carhart four-factor model as the Gao et al. (2020) study demonstrates that the momentum risk factor from the Carhart model is significant for only $8 \%$ of funds - and is insignificant on average.

7. Numerous alternative conditional beta and conditional alpha-beta models were estimated but the results are not presented to conserve space.

8. We also use the Fama French three-factor-based models to implement the bootstrap tests and obtain broadly similar findings to those presented in Table 5. Details of findings are not presented but are available on request.

9. Details of bootstrap findings regarding these alternative minimum fund histories are not presented (but are available on request) as the results remain almost unchanged with varying the number of minimum observations.

10. The results of fund performance during the sub-sample period of 2003-2006 are not presented in Table 6 but are available on request. This is because during 2003-2006 there were only 11 funds with at least 1-year returns per RESSET database, and hence ranking the 11 funds into $\max , 5 \% \max$, $10 \%$ max, etc., is meaningless. To avoid confusion, we drop the results over 2003-2006 from Table 6 but our results show that none of them displayed significant alpha under the $5 \%$ significance level, i. e. no informed fund managers.

11. The results of the extensions are not shown here but are available on request.

\section{References}

Berk, J.B. and Green, R.C. (2004), "Mutual fund flows and performance in rational markets", Journal of Political Economy, Vol. 112 No. 6, pp. 1269-1295, available at: http://finance.martinsewell.com/ fund-performance/BerkGreen2004.pdf

Blake, D. and Timmermann, A. (1998), "Mutual fund performance: evidence from the UK", Review of Finance, Vol. 2 No. 1, pp. 57-77, doi: 10.1023/A:1009729630606.

Calomiris, C., Fisman, R. and Wang, Y. (2010), "Profiting from government stakes in a command economy: evidence from Chinese asset sales", Journal of Financial Economics, Vol. 96 No. 3, pp. 399-412, available at: www-bcf.usc.edu/ yongxiaw/JFE2010.pdf

Carhart, M. (1997), “On persistence in mutual fund performance”, The Journal of Finance, Vol. 52 No. 1, pp. 57-82, available at: http://onlinelibrary.wiley.com/doi/10.1111/j.15406261.1997.tb03808.x/abstract

Chen, L. and Chen, H. (2017), "Applying a bootstrap analysis to evaluate the performance of chinese mutual funds", Emerging Markets Finance and Trade, Vol. 53 No. 4, pp. 865-876, doi: 10.1080/1540496X.2016.1152178.

Christopherson, J., Ferson, E. and Glassman, D. (1998), "Conditioning manager alphas on economic information: another look at the persistence of performance", Review of Financial Studies, Vol. 11 No. 1, pp. 111-142, doi: 10.1093/rfs/11.1.0111.

Cuthbertson, K., Nitzsche, D. and O'Sullivan, N. (2008), "UK mutual fund performance: skill or luck?”, Journal of Empirical Finance, Vol. 15 No. 4, pp. 613-634, doi: 10.1016/j. jempfin.2007.09.005. 
$\mathrm{RAF}$

20,5

296

Efron, B. and Tibshirani, R.J. (1993), An Introduction to the Bootstrap, Monographs on Statistics and Applied Probability, Chapman and Hall, New York, NY.

Fama, E. and French, K. (1993), “Common risk factors in the returns on stocks and bonds”, Journal of Financial Economics, Vol. 33 No. 1, pp. 3-56, doi: 10.1016/0304-405X(93)90023-5.

Fama, E. and French, K. (2010), "Luck versus skill in the cross-section of mutual fund returns", The Journal of Finance, Vol. 65 No. 5, pp. 1915-1947, doi: 10.1111/jofi.2010.65.issue-5.

Fama, E. and French, K. (2015), “A five-factor asset pricing model”, Journal of Financial Economics, Vol. 116 No. 1, pp. 1-22, doi: 10.1016/j.jfineco.2014.10.010.

Feng, Y. (2015), “The investor structure of Chinese stock market”, Business Culture, Vol. 12, pp. 101-102.

Ferson, W. and Schadt, R. (1996), "Measuring fund strategy and performance in changing economic conditions", Journal of Finance, Vol. 52 No. 2, pp. 425-462, available at: www.ntuzov.com/Nik_Site/ Niks_files/Research/papers/mut_funds/Ferson_and_Schadt_1996.pdf

Fletcher, J. and Forbes, D. (2002), "An exploration of the persistence of UK unit trusts performance", Journal of Empirical Finance, Vol. 9 No. 5, pp. 75-493, doi: 10.1016/S0927-5398(02)00006-3.

Gao, J., O'Sullivan, N. and Sherman, M. (2017), "Performance persistence in Chinese securities investment funds", Research in International Business and Finance, Vol. 42 No. 2017, pp. 1457-1477, doi: 10.1016/j.ribaf.2017.07.085.

Gao, J., O'Sullivan, N. and Sherman, M. (2020), “An evaluation of Chinese securities investment fund performance”, The Quarterly Review of Economics and Finance, Vol. 76 No. 2020, pp. 249-259, doi: 10.1016/j.qref.2019.08.007.

Grinblatt, M. and Titman, S. (1986), "Portfolio performance evaluation: old issues and new insights", Review of Financial Studies, Vol. 2 No. 3, pp. 393-416, available at: https:/EconPapers.repec.org/ RePEc:fth:pennfi:22-88

Han, F. (2012), "Empirical study on the performance evaluation of ETF in China", Master's dissertation, Southwestern University of Finance and Economics, (in Chinese).

Hendricks, D., Patel, J. and Zeckhauser, R. (1993), "Hot hands in mutual funds: short run persistence of performance, 1974-88”, The Journal of Finance, Vol. 48 No. 1, pp. 93-130, available at: www.jstor. org/stable/2328883?seq=1\#page_scan_tab_contents

Huang, H., Jiang, L., Leng, X. and Peng, L. (2020), "Bootstrap analysis of mutual fund performance", working paper, available at: https://ssrn.com/abstract=3513979

Jensen, M. (1968), "The performance of mutual funds in the period 1945-1964”, The Journal of Finance, Vol. 23 No. 2, pp. 389-416, available at: http://onlinelibrary.wiley.com/doi/10.1111/j.1540-6261.1968.tb00815.x/full

Kosowski, R., Timmermann, A., White, H. and Wermers, R. (2006), "Can mutual fund 'stars' really pick stocks? New evidence from a bootstrap analysis", The Journal of Finance, Vol. 61 No. 6, pp. 25512596, available at: https://papers.ssrn.com/sol3/papers.cfm?abstract_id=1974577

Luo, C. (2011), "Empirical analysis on performance of Chinese securities investment fund", Journal of Zhongnan University of Economics and Law, Vol. 188 No. 5, pp. 95-101, available at: http://caod. oriprobe.com/articles/28417149/wo_guo_zheng_quan_tou_zi_ji_jin_ji_xiao_de_shi_zhe.htm

Mamaysky, H., Spiegel, M. and Zhang, H. (2004), "Improved forecasting of mutual fund alphas and betas, Yale School of Management”, ICF Working Paper 04-23, available at: http://depot.som. yale.edu/icf/papers/fileuploads/2361/original/04-23.pdf

Merton, R.C. and Henriksson, R.D. (1981), "On market timing and investment performance II: statistical procedures for evaluating forecasting skills”, Journal of Business, Vol. 54 No. 4, pp. 513-33, doi: $10.1086 / 296144$.

Peng, M. (2001), "The resource-based view and international business", Journal of Management, Vol. 27 No. 6, pp. 803-829, doi: 10.1177/014920630102700611.

Peng, M. and Heath, P. (1996), "The growth of the firm in planned economies in transition: institutions, organizations, and strategic choice", Academy of Management Review, Vol. 21 No. 2, pp. 492-528. 
Quigley, G. and Sinquefield, R.A. (2000), "Performance of UK equity unit trusts", Joumal of Asset Management, Vol. 1 No. 1, pp. 72-92, available at: https:/link.springer.com/article/10.1057/palgrave.jam.2240006

Tonks, I. (2004), "Performance persistence of pension fund managers, University of Exeter, Centre for Finance and Investment", Working Paper, forthcoming Journal of Business 2005, available at: http://citeseerx.ist.psu.edu/viewdoc/download?doi=10.1.1.646.2710\&rep=rep1\&type=pdf

\section{Chinese securities investment funds}

Treynor, J. and Mazuy, K. (1966), “Can mutual funds outguess the market?”, Harvard Business Review, Vol. 44, pp. 131-136, available at: https://users.business.uconn.edu/jgolec/Treynor-Mazuy.pdf

Wermers, R. (2000), "Mutual fund performance: an empirical decomposition into stock-picking talent, style, transactions costs, and expenses", The Journal of Finance, Vol. 55 No. 4, pp. 1655-1703, doi: 10.1111/jofi.2000.55.issue-4.

Xiao, K. and Yang, Y. (2005), "Empirical analysis on performance and persistence among Chinese open-end securities investment funds", Finance and Trade Research, Vol. 2005 No. 2, pp. 55-59, available at: http:// caod.oriprobe.com/articles/794648/Performance_Persistence_of_Open_end_Funds_in_China.htm

$\mathrm{Xu}, \mathrm{N}$. and Liu, Z. (2009), "Can mutual fund really pick stocks? A bootstrap analysis", 2009 Second International Workshop on Knowledge Discovery and Data Mining, Moscow, pp. 381-384, doi: 10.1109/WKDD.2009.33.

Yan, S. (2020), "The evaluation of the lucky component of open-end fund performance based on bootstrap method", American Journal of Industrial and Business Management, Vol. 10 No. 05, pp. 1039-1057, doi: 10.4236/ajibm.2020.105069.

Yang, L. and Liu, W. (2017), "Luck versus skill: can Chinese funds beat the market?", Emerging Markets Finance and Trade, Vol. 53 No. 3, pp. 529-643, doi: 10.1080/1540496X.2015.1097951.

Zhao, J. (2012), "The studies on different incentive mechanism and the funds-performance in China", Ph. D. dissertation, Jilin University.

Zhao, X. and Wang, S. (2007), "Empirical study on Chinese mutual funds' performance", Systems Engineering - Theory and Practice, Vol. 27 No. 3, pp. 1-11, doi: 10.1016/S1874-8651(08)60020-4.

Zhou, Z. and Shi, B. (2004), "An empirical study of selectivity and market timing ability of open-end fund managers in China", Study of Finance and Trade, Vol. 6, pp. 92-97.

\section{Further reading}

Turner, A. (2004), Pensions: challenges and choices: the first report of the pensions commission, The Pensions Commission, The Stationary Office, London.

\section{Corresponding author}

Jun Gao can be contacted at: jun.gao@ucc.ie

For instructions on how to order reprints of this article, please visit our website:

www.emeraldgrouppublishing.com/licensing/reprints.htm

Or contact us for further details: permissions@emeraldinsight.com 